\title{
Why is Luxun's "Nora" Different: The Cultural Account for the Divergent Heroines Between A Doll's House and Lament Over the Dead
}

Fangming Gong

The School of Literature, Hunan University, the Southern Lushan Road, Changsha, Hunan, China

996985750@qq.com

\begin{abstract}
"Nora" is originally the heroine in Ibsen's A Doll's House who seeks for her dignity and independence by way of leaving her family. In 1925, Chinese leading writer Luxun imitated Nora's runaway and composed a novel Lament over the Dead. However, this work's heroine Zijun sinks to a miserable anti-hero as a result of her courage in runaway, which show a striking contrast to the original Nora. This thesis argues that the different cultural environment faced by Chinese and Northern European women in the early twentieth century causes the divergent expectations in the action of runaway between Luxun and Ibsen. The historical and cultural environment in Northern Europe benefits feminist movement and, therefore, becomes the fertile ground of feminist heroes. In contrast, the cultural environment in the time of Old Democratic Revolution hindered Feminist Movement in China, and punished the action of runaway. The above cultural difference is the vital reason for the distinct ending of the Luxun's Zijun and Ibsen's Nora. By his work, Luxun remonstrates that in China, the deliverance of the "Doll" in an old family demands much more than personal runaway because it would involve the fundamental transformation of the whole cultural environment.
\end{abstract}

Keywords: Luxun, Ibsen, A Doll's House, Lament over the Dead

\section{鲁迅的 “娜拉” 为何不同: \\ 《玩偶之家》与《伤逝》女主角形象差异的文化究因}

龚芳明

湖南大学文学院, 岳麓区麓山南路, 长沙, 湖南, 中国 996985750@qq.com

\section{摘要}

“娜拉”本是北欧作家易卜生的戏剧《玩偶之家》中出走自救的女权英雄。1925年鲁迅仿写“娜拉”出走创 作小说《伤逝》。然而《伤逝》中女主角子君却反为出走的胆气所害, 沦为凄苦没落的反英雄, 这与原 剧中的女权英雄娜拉大相径庭。本文认为二十世纪初中国、北欧妇女解放面临的不同文化环境决定了 两位现实主义作家对 “娜拉” 英雄与反英雄的相反阐释。北欧整体历史环境因其有利于妇女解放运动的 开展而成为创造女权英雄的沃土。而中国旧民主主义早期阶段的整体环境阻碍妇女解放的开展, 封锁 并扼杀“娜拉”式的出走行为。这是令鲁迅的子君与北欧易卜生的“娜拉”命运迥异的根本原因。因此, 在 中国, “家庭玩偶”的解救远非个人出走那么简单, 还涉及到文化环境的整体改造。由此可见, 超越个体 文本, 在历史的广阔语境下审视作品对于理解鲁迅这一文化关键人物的大局眼光、深远用心有着不可 忽视的意义。

关键词：鲁迅；易卜生；《伤逝》; 《玩偶之家》; 


\section{1 开拓创新的 “海盗文化”}

\section{1. 前言}

“娜拉” 本是易卜生剧作《玩偶之家》 ${ }^{[1]}$ 中的女主 角。身为平凡主妇, 她一度受到男权环境的蒙蔽。在爱 情幺灭后, 她转而追求女性独立的本体价值, 通过出走 自救，终结了自小以来 “家庭玩偶” 的命运。1918年, 在经过《新青年》专刊推荐后, “娜拉” 成为启蒙话语 重要成分。“娜拉” 成为负载反抗礼教、解放个性、重 建伦理等多重诉求的文化象征, 更激发了无数女性真正 “为人” 的梦想。全国上下当真有不少人 “砰” 的一声 关上了封建家庭或资本主义家庭的大门。“娜拉热” 成 为二十世纪二十年代的一个时代印记。

张春田指出: “启蒙话语的基本预设是： '出走” 一定会有 “自由”。只要思想觉醒, 接受自由、平等这 样的价值准则, 成为有个性的原子化个体, 就可以摆脱 一切旧有传统的束缚, 达到人性的自由解放, 并促使现 实的改善。” ${ }^{[2]}$ 这说明 “娜拉” 式的启蒙话语认为自由 前景可以通过单一的个人的出走获得实现。然而, 对于 “娜拉式” 启蒙梦想, 鲁迅却一反五四初期的乐观基调。 1923年, 他通过演讲《娜拉走后怎样》给予这场精神高 热当头棒喝。他尖锐地指出: 在中国女性出走只有两条 路可走 “要么堕落, 要么回来。” ${ }^{[3]}$ 结合鲁迅的创作背 景, 他一贯赞许易卜生 “以变革为生命” 的破旧胆气。 [4] 但为何鲁迅作品中的 “娜拉” 反为出走的胆气所害, 成为反英雄式角色, 以至于与易剧中的英雄 “娜拉” 形 象迥异呢?

本文认为, 两个” 娜拉” 的不同, 绝非单一的文 学现象, 而是一个洋为中用文化实践的现实问题。《玩 偶之家》所在的北欧与 《伤逝》 ${ }^{[5]}$ 所处的中国的历史环 境的巨大差异决定了 “娜拉行为” 英雄与反英雄两种截 然不同的姿态, 也因此有了两位现实主义作家对 “娜拉” 形象及命运的不同阐释。而以往评论对《伤逝》与《玩 偶之家》的比较多注重沿袭, 相异性比较即便有也往往 集中在文学或精神层面的分析, 对于 “娜拉现象” 在中 国、北欧之间的跨地域传播笽尤少有企及。因此，本文 将从二十世纪初中国与北欧的差异性文化环境来细致 探究鲁迅的 “娜拉” 不同面貌的现实缘由。

对于鲁迅和易卜生这两个干预现实、意在启蒙的文 化领袖而言, 文化语境往往渗透在作品的各个角落, 操 控着人物形象和命运, 借以传达作家的文化态度及启蒙 要义。从这一角度而言, 鲁迅的反英雄 “娜拉” 之所以 不同于易卜生的原版英雄, 在很大程度上是中国、北欧 的差异性文化语境导致的不同结果。

\section{2. 北欧语境的特征}

易卜生的娜拉的创作背景是北欧挪威, 北欧文化语 境具有如下两个特征:
北欧斯堪的纳维亚群岛地跨北极圈, 冬季长达6个 月左右。从十一月到二月, 黑夜于下午三点左右降临延 至次日10点。在地理环境上, 斯岛四面临海, 境内多冰 川峡谷。自然环境的险恶、黑暗与严寒使得偏居一隅的 古北欧人一直有摆脱峡湾谷地, 开拓新天地的心理。历 史上的北欧人曾无数次出征欧洲大陆。终于在 $6-10$ 世纪 以征服者的形象出现在欧洲, 迎来了阳光明媚的新家 园。这固然不乏北欧海盗的残酷性、侵略性, 但另一方 面也炼就了北欧奋发图强、开拓进取的民族精神。

所以，在《玩偶之家》中，娜拉告别旧世界，走向 新世界, 这在北欧文化中是一种非常熟悉的英雄姿态。 这也是为什么在该剧中, 对于妻子出走这一最大家庭变 故, 丈夫海尔茂反倒并未像之前受人威胁时那样气急败 坏, 而是对这种开拓新生的文化原型表现出默认与退 让。海尔茂作为娜拉身边重要的环境代表，他的反应表 明了北欧文化环境在深层心理上对娜拉行为的认可, 提 升了女主角的英雄气质。

\section{2 自由独立的个性}

19世纪前, 北欧的主体社会一直是自由农民。这一 点以挪威最为典型。挪威农民在历史上从未为奴，向来 享受自由的人身权利。挪威人民由此保留了自己独立的 个性与较为纯粹的情感心灵世界。恩格斯盛赞他们为 “真正的人。”

易卜生曾说: “诗人的使命是唤醒更多的人去实现 自由独立的人格”。 ${ }^{[6]}$ 他其实正是带着北欧文化的理想 原型去服务于个性解放, 心灵解脱。在娜拉身上, 同样 表现出这种独立自由的完整人格。当她愿意付出时, 她 天真热情, 用最完整的爱去付出。当她看破庸鄙不再付 出时, 她有独立的个性, 坚定地走向自由。在北欧文化 中, 这是一个有着完整个性的理想原型, 娜拉也藉此成 为易剧中最无可挑剔的主人公。

由此可见, 北欧文化鼓励开拓进取, 维护独立自由。 而根源于北欧理想原型的娜拉，作为妇女解放的启蒙形 象, 不但不会成为北欧文化中的异类, 反之还是这种文 化的精英代表。因此, 她注定要成为易剧中的英雄。

\section{3. 中国语境的特征}

然而在二十世纪初, 中国的基本面貌还是鲁迅笔下 的老中国，与培植娜拉的北欧文化有着巨大差异。当时 中国文化语境呈现出如下两个特点:

\section{1 “三从四德” 的大众女性观}

“娜拉” 所引发的妇女解放思潮虽然在五四青年中 反响剧烈, 然而刘王立明指出: “妇女运动只是少数知 识阶级的妇女在运动, 不是普遍运动”。 ${ }^{[7]}$ 妇女解放难 
大叙事所遮盖，更具有迷惑自我的欺骗性，造成了新女 性 “欲新还旧” 的尴尤姿态。

在《伤逝》中子君吸引滑生的是起初独立自主, 追 求自我价值的大无畏姿态。然而 “以智谋婚” 的目标一 经实现，她的新女性使命便告终结。婚后子君心安理得 依赖涓生，并甘居从属。在遭到涓生抛弃时，为爱付出 一切的子君仍旧没有人格觉醒, 不反抗, 不愤怒, 只是 在沉默中黯然离世, 完全无异于旧式女子。可谓新一时, 旧一世。这种姿态不仅消解了涓生眼中的 “新人”魅力, 否定了自我价值，更让旧式女性的边缘命运再次回归， 并且更为悲惨。对于旧式法则而言, 出走离经叛道。对 于新式法则而言, 她懦弱无为。所以一朝失意, 难以自 拾。刘王立明指出: “进来常有人说: 女子可复本来面 目了。事实恰恰是与此相反。尤其年轻女子, 有史以来 再没有像当代这样不安定。” ${ }^{[11]}$ 《伤逝》可以说以一个 个案诠释了 “欲新还旧” 的半截子解放观带来的坎坷命 运。这种迷惑自我的 “新” 无疑也给真正的妇女解放带 来重重障碍。

由此可见，在二十世纪的中国，一来 “三从四德” 的大众女性观给新女性带来环境压迫, 二来新女性自身

“欲新还旧”, 深层性别意识仍由旧道德, 旧法则统领, 依赖重重, 这严重阻碍个体意识的深度觉醒。由《伤势》 可见当时中国女性真正的解放远非个人出走那么简单, 还需变革被启蒙话语遮蔽的环境和个体自身的局限。因 此, 北欧文化中娜拉离家出走, 追求新生的姿态只是在 浅薄层面顺应了五四激进破旧的需求。当她带着妇女解 放的符码和当时的中国文化语境发生深层接触时, 不可 避免要在旧文化的重压之下沦为颓唐没落的反英雄。

\section{REFERENCES}

[1] Ibsen, Henrik, A Doll's House[M], New York: E. P. Dutton \& Co, 1997.

[2] Zhang, Chuntian. From Nora's Runaway to China's Transformation: on the Relationship Between Luxun and the Enlightenment Discourse[J]. Theory and Criticism of Literature and Art, 2008, (2):38-43.

[3] Luxun. How is "Nora" after her Runaway[M]. The Complete Works of Luxun, Beijing: People's Literature Publishing House, 1981.100,101.

[4] Gao Zhongfu, Essays on Ibsen[M]. Beijing: Foreign Language Teaching and Research Press,1982. 6.

[5] Luxun, Lament over the Dead[M]. The Complete Works of Luxun, Beijing: People's Literature Publishing House, 1981. 164.

[6] Ibsen, Henrik. Letters and Speeches of Ibsen[M]. Beijing: People's Literature Publishing House, 2012, 181. 
[10] Liu Wangliming. China's Feminist Movement[M]. Beijing: The Commercial Press, 1933. 65.

[11] Liu Wangliming. China's Feminist Movement $[\mathrm{M}]$. Beijing: The Commercial Press, 1933.66.

[9] Yang Zhihua. A Survey of Feminist Movement[M]. Shanghai: East Asia Library, 1927. 24. 